\title{
First case report of dermatitis associated with Leporacarus gibbus in cat
}

\author{
Mirabela Oana Dumitrache ${ }^{*} \mathbb{D}$, Adriana Györke, Gianluca D’Amico and Viorica Mircean
}

\begin{abstract}
Background: Leporacarus gibbus is a highly specific acarian parasitizing in rabbits, with a proven zoonotic potential. While the majority of cases of $L$. gibbus infestation are asymptomatic, several cases of pruritic cutaneous condition in both laboratory and pet rabbits were reported. Up to date, L. gibbus has not been linked with clinical signs in any other species than rabbits and humans.

Case presentation: This case report described the clinical case of a 14-month-old cat with a dermatitis linked to $L$. gibbus. Mites specimens were collected by brushing, followed by light microscopy examination and species identification. To the best of our knowledge, this is the first report of L. gibbus-related dermatitis in cat.

Conclusions: L. gibbus infestation should be considered as a possible differential diagnosis of pruritic skin conditions in cat.
\end{abstract}

Keywords: Leporacarus gibbus, Cat, Dermatitis

\section{Background}

Leporacarus gibbus (formerly Listrophorus gibbus), the rabbit fur mite, belongs to the family Listrophoridae, division Psoroptida, order Astigmata [1]. The life cycle of the parasite is characterized by a complete metamorphosis and occurs entirely on the rabbit coat. L. gibbus feeds on sebum and skin epithelial cells. Different studies questioning its pathogenicity. Due to the asymptomatic evolution of the majority of cases, L. gibbus is also considered as commensal, which can be commonly found on the rabbits' skin [2, 3]. Despite of being considered as a cosmopolitan species for both wild and domestic rabbits in Europe, only few studies are available on this topic. There is a lack of epidemiological studies and reports of L. gibbus in many countries. In addition, the description of the life cycle and contamination method remained unclear for many years [3]. It is though that $L$. gibbus is generally well tolerated by the rabbit host, but

* Correspondence: mirabela.dumitrache@usamvcluj.ro

Department of Parasitology and Parasitic Diseases, University of Agricultural Sciences and Veterinary Medicine Cluj-Napoca, Calea Mănăştur 3-5,

Cluj-Napoca 400372, Cluj, Romania a hypersensitivity reaction could determine the occurrence of clinical signs [4]. L. gibbus has been occasionally reported as the aetiological agent of a pruritic cutaneous condition in both laboratory and pet rabbits. Clinically, this ectoparasitosis is characterized by pruritus, moist dermatitis, poorly demarcate alopecia, erythema and scaling on the dorsum and hindlimbs $[3,5]$. Although it is considered as uncommon in humans, several case reports confirmed its zoonotic potential [5]. Up to date, $L$. gibbus has not been linked with clinical signs in any other species than rabbits and humans $[1,5]$.

\section{Case presentation}

A 14-month-old, sterilised female Ragdoll cat, only pet, living indoor, was presented with a history of one year of pruritus. The anamnesis revealed that the cat was purchased online a year ago and the owner observed the presence of generalised pruritus, the lack of hair on the tail and face, and black cerumen in the both ears during the first few days following acquisition. At that time, the patient was diagnosed by a primary care veterinarian with otodectic mange. The treatment applied was a

(c) The Author(s). 2020 Open Access This article is licensed under a Creative Commons Attribution 4.0 International License, which permits use, sharing, adaptation, distribution and reproduction in any medium or format, as long as you give appropriate credit to the original author(s) and the source, provide a link to the Creative Commons licence, and indicate if changes were made. The images or other third party material in this article are included in the article's Creative Commons licence, unless indicated otherwise in a credit line to the material. If material is not included in the article's Creative Commons licence and your intended use is not permitted by statutory regulation or exceeds the permitted use, you will need to obtain permission directly from the copyright holder. To view a copy of this licence, visit http://creativecommons.org/licenses/by/4.0/ The Creative Commons Public Domain Dedication waiver (http://creativecommons.org/publicdomain/zero/1.0/) applies to the data made available in this article, unless otherwise stated in a credit line to the data. 
single spot-on application of $45 \mathrm{mg}$ selamectin (Stronghold ${ }^{\circ}$, Zoetis) that lead to clinical resolution of the otodectic mange and skin lesions, and a substantial improvement of the generalised pruritus. The later symptom persisted at a low level of intensity during the following months. Furthermore, transitory digestive signs (vomiting, diarrhoea) occurred. At the age of 13 months, an intensification of the pruritus was observed. The owner linked this event with the antirabic vaccination. The same practitioner recommended an exclusion diet with an anallergenic food and two doses of dexamethasone (Dexamethasone ${ }^{\circ}$, Kepro) administrated at 3 days interval. After a month of therapy, the case was referred to our clinic because only a slightly improvement of the symptoms has been noticed.

At the moment of presentation, the clinical examination revealed a self-induced alopecia on the abdomen, the presence of papulosquamous lesions in the same region (Fig. 1), and gingivitis (Fig. 2).

Both skin scrapings and scotch test proved negative. However, stereomicroscope examination of the coat brushing revealed the presence of several mites. The image of a female mite at a low power objective (3x) is provided (Fig. 3). The mite specimens were collected and the microscopic examination using the 10x objective confirmed the presence of L. gibbus based on the following morphological characteristics: subcylindrical body, finely striated cuticle, sclerotised gnathostoma, two striated membranous flaps at each of the coxae of the first pair of legs, and presence of two elongated adanal processes and distinct adanal suckers in males (Fig. 4a) [3]. No other mite species were visualized. For comparison, a L. gibbus male collected from a rabbit is provided (Fig. 4b). In order to confirm the morphological species identification, the genomic DNA was extracted from specimens collected from the cat $(n=2)$ and from the rabbit $(n=10)$, by using a commercial kit (Isolate II

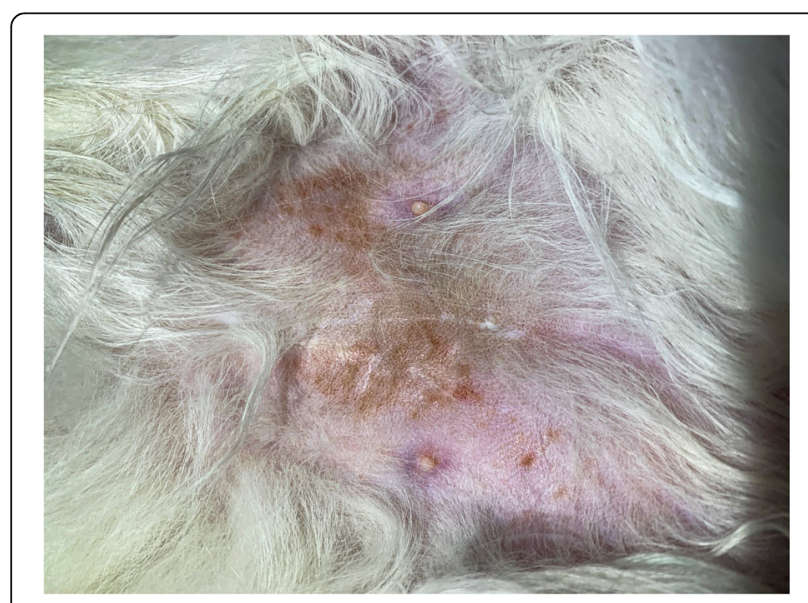

Fig. 1 Ventral aspect of a cat infested with L. gibbus

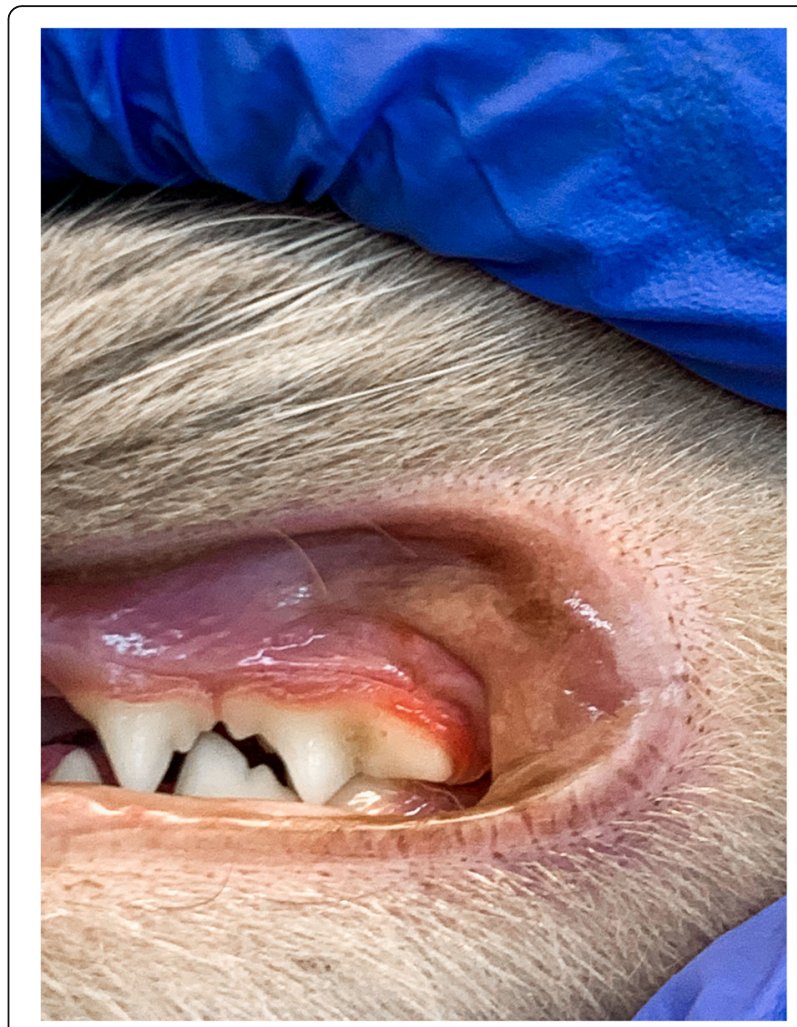

Fig. 2 Gingivitis associated with L. gibbus infestation in a cat

Genomic DNA Kit, Bioline, London, UK) following the manufacturer's instructions. The COI gene fragment was PCR-amplified using primer pairs bcdF05/bcdR04 $[6,7]$. The PCR products were purified using FavorPrep GEL/ PCR Purification Mini Kit (Favorgen Biotech Corp., Taiwan) and further sequenced (Macrogen Europe). The obtained sequences were compared with the available sequence in GenBank (acc. no. GQ864335.1). The BLAST analysis showed $92.39 \%$, and $92.21 \%$ similar degree

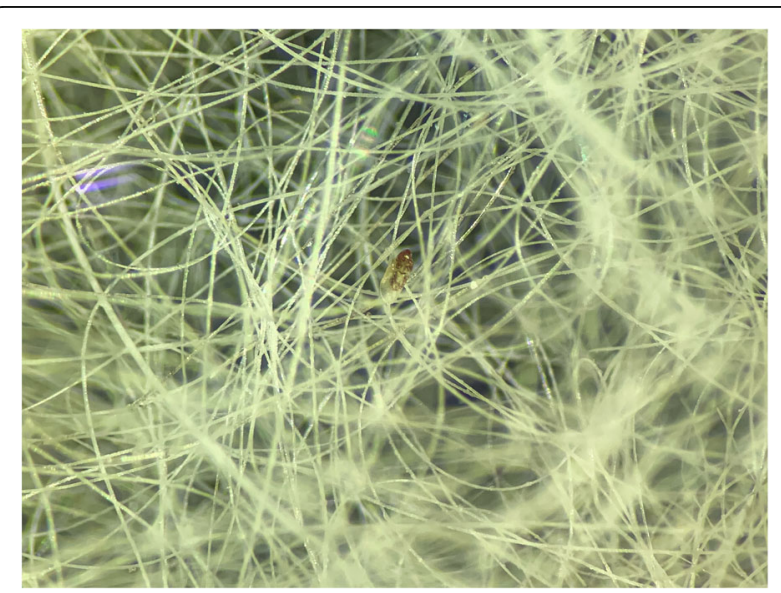

Fig. 3 Stereomicroscope examination of the coat brushing 


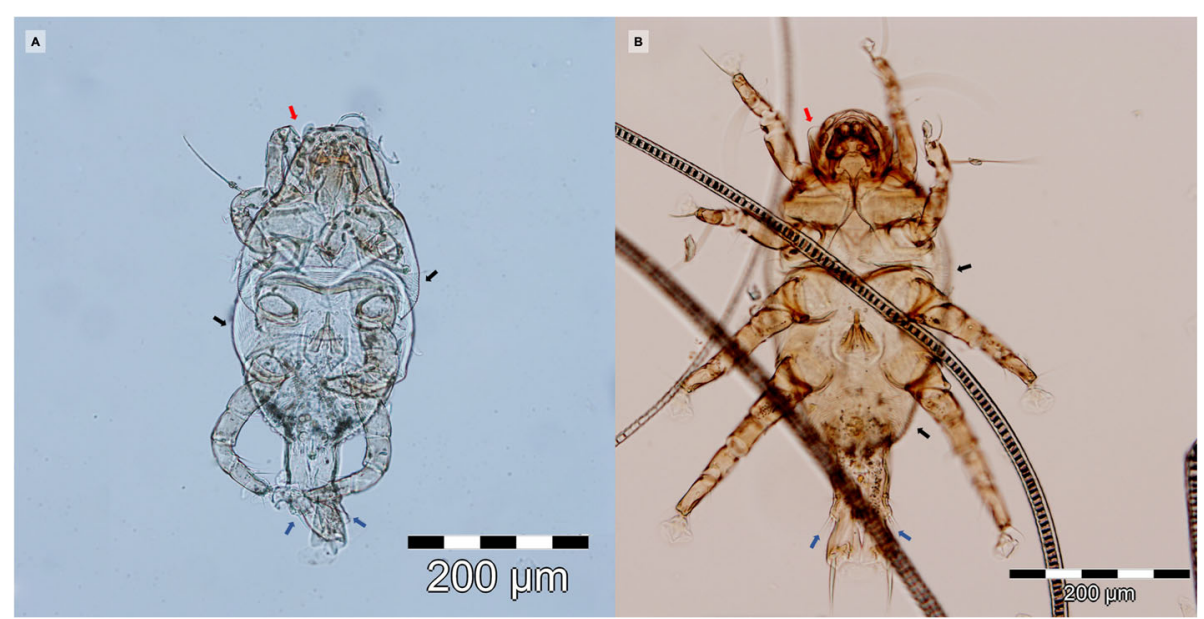

Fig. 4 Microscopic image of L. gibbus male, from cat (a) and from rabbit (b), showing finely striated cuticle (black arrows), sclerotised "dark hooded" gnathostoma (red arrow), two elongated adanal processes (blue arrows)

identity with L. gibbus for the cat, and rabbit strains respectively. The sequences obtained in this study from the parasites collected from the cat and from rabbits were submitted to the GenBank database under the following accession numbers: MW286180 and MW286214, respectively.

To evaluate one of the most common causes of immunosuppression in cats [8], a rapid test for FIV/FeLV infections (SNAP FIV/FeLV Combo Test, IDEXX) was carried out, but tested negative. The cat was treated with two spot-on applications of $45 \mathrm{mg}$ selamectin (Stronghold ', Zoetis) at two weeks interval, a protocol proved to be effective by Birke et al. [1]. Coat brushing tested negative for mites at 7 days after the second dose of selamectin. The skin lesions and the pruritus disappeared within the first 14 days of treatment. The owner did not show any lesions on the course of the disease evolution nor at the time of rabbit examination.

\section{Discussions and conclusion}

Although pruritus is a frequent sign of dermatological conditions in cats, this species develops less relevant diagnostic lesions than those observed in dogs. Moreover, the primary inflammatory lesions that may be present and could be relevant for identification of the pruritus cause are frequently transformed in secondary lesions due to the different behaviours triggered by itch (e.g. scratching, licking) [9]. Given this, the diagnosis approach of a pruritic skin condition should be made according to the cutaneous reaction patterns [9]. The causes of pruritus in cats are various, such as hypersensitivity dermatitis, ectoparasites, fungal infections, bacterial infections, or cutaneous reaction to systemic diseases $[9,10]$. As diverse as the causes are, as various the clinical patterns are: eosinophilic syndrome, miliary dermatitis, head and/or neck excoriation, regional or generalized scaling and/or crusting dermatoses, and symmetrical self-induced alopecia [10]. Nevertheless, for the development of an efficient treatment approach of feline pruritus, the case history might be of a great importance.

In this case report, the history of the cat, its origin, the young age, the lack of anti-parasitic treatments, and the clinical presentation with the self-induced alopecia clinical pattern suggested a parasitic disease as first hypothetical diagnosis, followed by hypersensitivity dermatitis that could have been caused by flea bite, cutaneous adverse food reactions, and/or atopic dermatitis [10]. Cats with nonseasonal pruritus and suggestive clinical patterns should undergo a dietary elimination-challenge trial to determine the importance of food allergen in the aetiology of a condition [10]. A restriction diet of 6 to 8 weeks is recommended to be followed. In our case, the cat was already following a strict diet with anallergenic food at the time of the initial examination. The lack in clinical signs improvement following the exclusion diet and anti-pruritic treatment with corticosteroids allowed us to eliminate food allergy as a hypothetical diagnosis. It is well known that in cats with food allergy, pruritus, which is the main complain of owners, is corticoidresistant in the majority of cases [11]. Altogether, the parasitic aetiology remained a possible cause and additional diagnostic test were performed to confirm or to exclude fleas' infestation, cheyletiellosis, demodicosis, pediculosis and/or Lynxacarus radovskyi infestation.

While skin scrapings and scotch test yielded negative results, the stereomicroscope examination of the coat brushing confirmed our hypothesis of a parasitic skin 
condition by revealing the mites. Initially, we suspected an infestation with $L$. radovskyi, due to the similar morphology of the mites and classification in the same family [12]. The presence of some uncharacteristic morphological features, as well as the few cases reported in the scientific literature [13] and L. radovskyi distribution in tropical regions [14] leaded us to perform a more detailed examination. Surprisingly, the microscopic identification based on the morphological characteristics revealed $L$. gibbus as the aetiological agent. Given that the cat was living exclusively indoor and considering its origin, we can assume that the contamination occurred through the close contact with infested rabbits from the pet shop. Diagnosis of L. gibbus in rabbits is challenging because the tape test could be inefficient due to the localization of the parasite on the first third of the hair shaft. This seems to be the principal cause of underdiagnosis in rabbits [1] and might explain why the scotch test we performed was negative in cat.

L. gibbus has a zoonotic potential and it has been linked twice with papular eruptions in humans $[5,15]$. Both reports highlight the difficulty in demonstrating the aetiology of the lesions in rabbit's owners because no mites were detected on their skin. In one report, the owners' dermatologist admitted a possible parasitic aetiology and suggested that the pruritic erythematous papules were most likely the result of a hypersensitivity reaction to mites' biting [5]. Morover, the resolution of the owners' skin lesions following the specific treatment of rabbits is an indirect, but substantial proof for that incriminates L. gibbus [5]. Despite of being considered as a common parasite of rabbits or even a commensal of this species, only few reports on the zoonotic character of $L$. gibbus are available. Hence, we can suspect that that the zoonotic transmission is linked to a certain immunologic status of the owner, like in the case of other mites [16], or uncommon.

Several treatment methods against $L$. gibbus have been proposed [1, 2, 17]. Although both imidocloprid plus permethrin and selamectin proved to be effective against this parasite, selamectin seems to eliminate the infestation more rapidly and is considered that a single selamectin application has a $100 \%$ efficacy against L. gibbus. However, some authors recommend monthly treatment until no live mites are detected [16]. These reports could explain the results obtained in our case. The first spoton treatment most likely has eliminated most of the parasites and allowed a temporary improvement of cat's condition. As no other treatment followed this first administration, the few parasites remaining on the skin continued their lifecycle and determined a low intensity but permanent pruritus during the following months. The exacerbation of pruritus following vaccination could be related to the stress associated with this procedure.
Infestation with other mites such as $L$. radovskyi in cats, were previously associated with gastrointestinal signs, gingivitis, fever, vulvitis/proctitis, weight loss, etc. [12]. However, as now other similar cases are reported, it is difficult to correlate the presence of the nondermatological signs identified in our patient, with $L$. gibbus infestation. However,

The findings of this case report suggest that L. gibbus infestation, although uncommon, should be considered as a possible differential diagnosis of pruritic skin conditions in cat.AbbreviationPCR: polymerase chain reactions; FIV: feline immunodeficiency virus; FeLV: feline leukemia virus.

\section{Acknowledgements}

Not applicable.

Authors' contributions

MOD wrote the manuscript. AG and VM performed the clinical examination of the cat. GD and MOD collected the parasites and performed the morphological identification. VM designed the manuscript. All authors have read and approved the manuscript.

\section{Funding}

The research was funded by USAMV Cluj-Napoca Internal Grant number 6270/2017. and by the Ministry of Research and Innovation of Romania, Projects for Financing the Excellence in CDI, Contract no. 37PFE/06.11.2018.

Availability of data and materials

All relevant data are within this paper.

Ethics approval and consent to participate

Not applicable.

\section{Consent for publication}

The cat owner provided written consent for publication.

\section{Competing interests}

The authors declare that they have no competing interests.

Received: 6 May 2020 Accepted: 18 November 2020

Published online: 06 January 2021

\section{References}

1. Birke LL, Molina PE, Baker DG, Leonard ST, Marrero LJ, Johnson M, Simkin J. Comparison of selamectin and imidacloprid plus permethrin in eliminating Leporacarus gibbus infestation in laboratory rabbits (Oryctolagus cuniculus). J Am Assoc Lab Anim Sci. 2009;48(6):757-62.

2. Hansen $\mathrm{O}$, Mencke $\mathrm{N}$, Pfister $\mathrm{K}$, Beck W. Efficacy of a formulation containing imidacloprid and permethrin against naturally acquired ectoparasite infestations (Ctenocephalides felis, Cheyletiella parasitovorax, and Listrophorus gibbus) in rabbits. Int J Appl Res Vet M. 2006;4:4: 320

3. Kirwan AP, Middleton B, Mcgarry JW. Diagnosis and prevalence of Leporacarus gibbus in the fur of domestic rabbits in the UK. Vet rec. 1998; 142:20-1.

4. Patel A, Robinson KJE. Dermatosis associated with Listrophorus gibbus in the rabbit. J Small Anim Pract. 1993;34.8:409-11.

5. d'Ovidio D, Santoro D. Leporacarus gibbus infestation in client-owned rabbits and their owner. Vet Dermatol. 2014;25(1):46-e17.

6. Dabert J, Ehrnsberger R, Dabert M. Glaucalges tytonis sp. n. (Analgoidea: Xolalgidae) from the barn owl Tyto alba (Strigiformes: Tytonidae): compiling morphology with DNA barcode data for taxon descriptions in mites (Acari). Zootaxa. 2008;1719:41-52.

7. Dabert M, Witali nski W, Kazmierski A, Olszanowski Z, Dabert J. Molecular phylogeny of acariform mites (Acari, Arachnida): strong conflict between phylogenetic signal and long-branch attraction artifacts. Mol Phylogenet Evol. 2010;56:222-241. 
8. Hartmann K. Clinical aspects of feline retroviruses: a review. Viruses. 2012; 4(11):2684-710.

9. Foil CS. Differential diagnosis of feline pruritus. Vet Clin North Am Small Anim Pract. 1988;18(5):999-1011.

10. Hobi S, Linek M, Marignac $G$, et al. Clinical characteristics and causes of pruritus in cats: a multicentre study on feline hypersensitivity-associated dermatoses. Vet Dermatol. 2011;22(5):406-13.

11. Verlinden $A$, Hesta M, Millet $S$, Janssens GPJ. Food allergy in dogs and cats: a review. Crit Rev Food Sci Nutr. 2006;46(3):259-73.

12. Foley RH. An epizootic of a rare fur mite in an island's cat population. Feline Pract. 1991;19.3:17-9.

13. Jayanthy C, Nagarajan B, Latha BR. Cat fur mite Lynxacarus radovskyi in India. J Parasit Dis. 2017:41(4):1102-4

14. Ketzis JK, Dundas J, Shell LG. Lynxacarus radovskyi mites in feral cats: a study of diagnostic methods, preferential body locations, co-infestations and prevalence. Vet Dermatol. 2016;27(5):425-e108.

15. Burns DA. Papular urticaria produced by the mite Listrophorus gibbus. Clin Exp Dermatol. 1987;12:200-1.

16. Jefferson RV, Fusaro AE, da Silva Duarte AJ, Sato MN. Preconception maternal immunization to dust mite inhibits the type I hypersensitivity response of offspring. J Allergy Clin Immunol. 2003;111(2):269-77.

17. Hughs JE. Diagnosis and treatment of selected rabbit dermatologic disorders. Exotic DVM. 2004;5.6:18-20.

\section{Publisher's Note}

Springer Nature remains neutral with regard to jurisdictional claims in published maps and institutional affiliations.

\section{Ready to submit your research? Choose BMC and benefit from:}

- fast, convenient online submission

- thorough peer review by experienced researchers in your field

- rapid publication on acceptance

- support for research data, including large and complex data types

- gold Open Access which fosters wider collaboration and increased citations

- maximum visibility for your research: over $100 \mathrm{M}$ website views per year

At $\mathrm{BMC}$, research is always in progress.

Learn more biomedcentral.com/submissions 